Open Access

\title{
Collaborative workshop between client and agency for open innovation
}

\author{
Hyejeong Choi, Youngok Jeon, Hyerim Park and Ken Nah ${ }^{*}$
}

\author{
* Correspondence: \\ knahidas@gmail.com \\ Hongik University, Seoul, South \\ Korea
}

\begin{abstract}
Innovation should be promoted by effectively managing the human factors. In the past, efforts have been made aiming to innovate by utilizing either internal or external resources. In order to innovate, there needs a circumstance where ideas can overflow as many as possible, and to look at the problem from various perspectives to find possible solutions. In this context, some discussions have arisen on how to effectively communicate and share ideas between client and agency. It is expected that collaborative workshop model can become an appropriate solution for this object. It is necessary to define a new relationship between client and agency conducive to solve design problems. To such a degree, collaborative workshop would be an effective method for achieving open innovation.

This research was conducted on this key question - How the client and agency as collaborative partner can co-create innovation? How the collaborative workshop can influence the open innovation? What is the purpose of collaborative workshop? What is the process would be like? How the collaborative workshop can influence the relationship between client and agency? The research framework is as follows. Based on a literature review on the issue of collaborative workshop for open innovation, three case studies of collaborative workshop were conducted. With organizations like Crown Haiti, ISTN and Museum San among different backgrounds and workshop objectives, the results of their collaborative workshop and its processes have been compared and analyzed. In order to understand the process and its effects in collaborative workshops, a set of keywords that can describe all the behaviors and objectives in the process of three workshops are discovered. It is observed that all the keywords can be classified into several groups. This is compiled into four categories - enhancing common understanding, accelerating ideation, rapid testing, and sharing direction. The collaborative workshop model has brought forth that maps the goals and process of the collaborative workshop. It is necessary to concisely follow through each step at each category of the workshop. So the workshop includes the process of achieving each purpose.
\end{abstract}

\section{Introduction}

Creating sustainable innovation is the most substantial issue that directly relates to the survival of the organization. This being the case, it is essential for organizations to come up with new ideas, which is their everlasting and ongoing task that never ends. To the extent of generating ideas, innovation should be promoted by effectively managing the human factors. In the past, efforts have been made aiming to innovate organization by utilizing either internal or external resources. However, Kim et al.

(c) The Author(s). 2018 Open Access This article is distributed under the terms of the Creative Commons Attribution 4.0 International License (http://creativecommons.org/licenses/by/4.0/), which permits unrestricted use, distribution, and reproduction in any medium, provided you give appropriate credit to the original author(s) and the source, provide a link to the Creative Commons license, and indicate if changes were made. 
(2017) insisted that "The traditional closed innovation paradigm is no longer operating in the management and development of creative economy." The world is changing from the past times of promoting ideas from internal human resources or entrusting it completely to external agencies to the era of open innovation that creates innovation through the synergy of sharing ideas among internal and external human resources (Kodama and Shibata, 2015; Lee et al, 2016). In order to innovate, there needs a circumstance where ideas can overflow as many as possible, and to look at the problem from various perspectives to find possible solutions (Brown and Wyatt, 2010). In this context, some discussions have arisen on how to effectively share ideas between client and agency.

The group ideation tools have been developed a long time ago. However, because the role of client and agency has clearly been separated and there is a strong perception that only agency must create ideas, collaborative workshop between client and agency has not been well established to draw ideas together (Beard, 1996). In the age of open innovation, as the need for sharing ideas among external groups began to emerge, a workshop was suggested in the study to break the roles of client and agency for problem solving and develop ideas together.

In general, the effects of workshops in precedent studies have been explored, but research on collaborative workshops that redefine the role between client and agency and open innovation has been lacking. The purpose of the study is not only exploring the effect of collaborative workshop between client and agency by analyzing three workshop cases but also suggesting a collaborative workshop model that can be used in various problem-solving environments.

\section{Research questions}

How to effectively utilize human factors will significantly influence on organizational innovation. In spite of the increasing significance of innovation, various idea generations are considered as a mandatory factor and thus, open innovation has become very crucial than before. Accordingly, this research is focused on identifying answers for several subsequent questions based on one primary question as follows.

Primary question: How the client and agency as collaborative partner can co-create innovation?

- Subsequent question.1: How the collaborative workshop can influence the open innovation?

- Subsequent question.2: What is the purpose of collaborative workshop? What is the process would be like?

- Subsequent question.3: How the collaborative workshop can influence the relationship between client and agency?

\section{Literature review}

\section{Human resource management and open innovation}

Creation of innovation signifies creative idea thinking. On the parcel of exploring creativity, how to utilize human resource is essential and further research is strongly required. Nah (2017) pointed out the three factors of innovation: personal/group creativity, 
technology, in other words, the process, and culture of possibilities. Among these factors, the creativity of individual or group, namely, the human resource is the single most significant factor than any other ones.

In the meantime, human resources are limited for each organization. It is necessary to consider a countermeasure that needs to be implemented. So far, there were two ways in which organizations could utilize human resources to fulfill innovation. First, innovation was established both in innovative strategy and implementation through internal or private members of an organization. This is the reason why organization handles the process of design strategy and implementation internally. This is also a way to promptly respond to a rapidly changing market environment. Second, external resources were utilized to build up limited resources. The role of client and agency was transparent and clear. A client is a system that gives an authority to a professional group of agencies to solve problems and pays a price for it. Consequently, these two approaches utilize either one of internal or external resources. On that account, this is a form of closed innovation. The characteristics of this closed innovation reveals the limitations so that many organizations are out to achieve open innovation through multilateral information or sharing technology.

User innovation, customer innovation, collective intelligence, crowdsourcing and open source innovations will be referred to as open innovation (OI) in that they are innovation based on the transfers across the boundaries of knowledge and technology (Yun et al., 2016). Nho (2016) insisted that "Open innovation explains why knowledge sharing and cooperative work between in and out-bound of organizations are important." In this context, some specific implementation plans are examined for open innovation of collaborating. This study introduces the collaborative workshop as a method for open innovation in which clients, agencies, and other stakeholders could work together as a whole.

\section{Collaborative workshop and open innovation}

Chesbrough (2003) insisted that open innovation is the usage of knowledge inflow and outflow from the corporation to accelerate internal innovations and maximize their value by enlarging the market for external utilization. There have been various studies to utilize external ideas in the dynamics of open innovation (Martin, 2009; Witt, 2016). And collaborative workshop is one of the efficient tools for open innovation. Various problem-solving solutions can be gained in a short period of time.

According to the dictionary definition, workshop is defined as "a usually brief intensive educational program for a relatively small group of people that focuses especially on techniques and skills in a particular field (Merriam-webster Dictionary)." Workshop is used to refer to the activities in which a group of people gathers in a spot where organization offers an educational program for their employees or as if when tons of possible ideas are needed in a short period of time.

The beginning of collaborative workshop is Brainstorming, the group ideation tool. Osborn (2007) suggested rules of idea meetings to help employees think creatively about their advertising campaigns. It is a tool to raise the diversity of ideas for problem solving according to the principle of 'quantity breeds quality' (Jung et al, 2015). Since that, similar group ideation tools such as Brainwriting and Gordon Method have been developed. In recent years, it is used as a way of problem solving in various company situations to create many ideas in a 
short time under the name of workshop. Workshop can contain many different types of tool for ideation such as image mapping and prototyping.

The effect of the workshop is to gather various stakeholders and externalize their thoughts to find solutions. Through workshops, stakeholders could clarify unclear ideas and develop a train of thoughts in detail, share ideas and values with them, encourage each other and strengthen one another to build on each other's ideas. Indeed, this can essentially take full advantage of the externalization process. Kolko (2015) insisted that this serves as a method of externalization, albeit through conversation rather than formal process. Furthermore, workshops make a synergy on ideation process. As they are motivated by such process of ideation, like a cog in the wheel, they can be encouraged to help each other by building on one another's ideas to construct, finding problems from different perspectives and grasp new solutions.

Workshop is an activity in which a plurality of stakeholders from external organizations gathers all together in a space to find alternatives to solve organizational problems within a short period of time. Recently, as collaborations among stakeholders have encouraged for innovation in relation to various organizational problems (Terwiesch and Loch, 2004), collaborative workshop could support as a tool for collaborations. In this study, the term, 'collaborative workshop' is used to emphasize the collaboration form of workshop between client and agency.

\section{Collaborative workshop between client and agency}

Companies that understand the effectiveness of workshops are working on various workshops internally to solve problems, but are still reluctant to do workshops between external stakeholders. Collaborative workshops are available for a variety of participants. The reason for studying workshops between clients and agencies in this study is that although the workshops between the two stakeholders are important, they usually do not realize their importance. So far, their roles have been clearly distinguished. Researchers and project managers such as Shaw (2016) and Gibson (2016) insisted on collaboration between client and agency. In order to find innovative and true problem-solving ideas, client and agency need to find efficient methods for open innovation. The effectiveness of the above mentioned workshops could be applied to collaboration between client and agency.

\section{Research methods}

This study focuses on introducing a collaborative workshop model through three case studies. The scope, content, and research method of this study are described as follows (See Fig. 1). First, literature review was conducted on the research issue of collaborative workshop for open innovation. Human factors are examined - a factor that influences the level of innovation the most. Then, the effect of collaborative workshop, concerning human factors toward open innovation in the role and work method between client and agency has been analyzed. Second, three case studies of collaborative workshop are analyzed. With organizations like Crown Haiti, ISTN and Museum San among different backgrounds and workshop objectives, the results of their collaborative workshop and its processes have been compared and analyzed.

For the case study, three Korean companies were selected which conducted workshops with their agencies. The three companies selected for the case study are 
companies doing business in different sectors. In Korea, it is not easy to find several companies that have conducted collaborative workshops between client and agency in one business area. In this study, the role and the process of collaborative workshop between client and agency in different situations of different companies is examined. A collaborative workshop model was developed with the result of comparing and analyzing common points and differences in various cases.

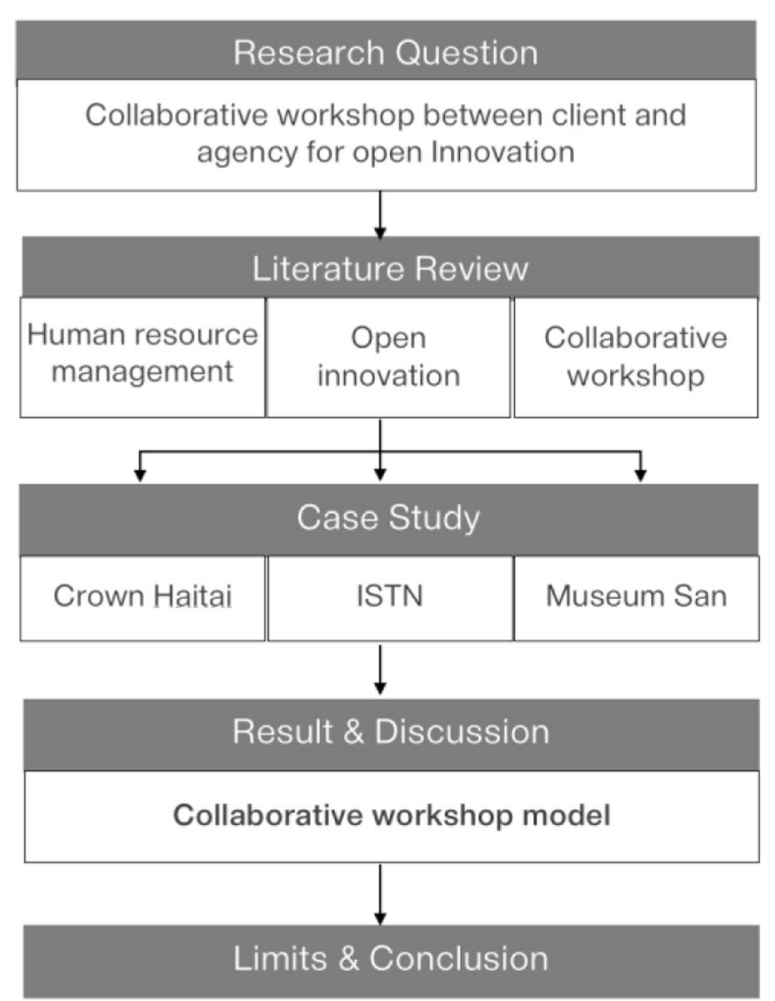

Fig. 1 The Research Framework

Major similarities and differences have been documented through comparing and analyzing the process of those three workshop cases. Some keywords are selected from the characteristics of the workshop process and result, and then they were categorized. Regards to this, common features between the constant effects that collaborative workshop has and its constant processes are described. Throughout the theoretical research and case studies, the relationship between client and agency as well as finding a significance of collaborative workshop for open innovation has been reset. Based on the real-life case studies, the process of collaborative workshop, the role of client and agency and the result obtained during the course of workshop are outlined. And consequently, a collaborative workshop model that can be further utilized for open innovation on various organizational problems in the future is proposed. The effects of workshop cannot be measured or counted quantitatively. And in general, its effect does not appear immediately. Workshop often takes times to get the final result since it mostly starts on an early stage of the design process to understand problems, to come up with ideas quickly and efficiently and to address design direction. There also may be comprised of multiple variables after the workshop. Some relevant professionals can often run through an additional ideation process and create result from the agency side, 
thus certain circumstances of client could vary. So in consequence, the results of the workshop may or may not be directly reflected in the final output. Although it is not directly reflected, the objective of the workshop is to ultimately improve the quality of the final output, but also has a purpose of facilitating the design process such as drawing out inherent ideas of stakeholders. The number of cases in this study is limited, so the results may be somehow limited as well.

\section{Case study}

In this study, three different cases of collaborative workshop were analyzed based on the following literature reviews to look for its significance and method of real-life progress. An analysis on three collaborative workshop cases with different backgrounds and objectives will focus into the process and its significance of collaborative workshop in overall.

\section{Crown Haitai}

\section{Company overview}

Crown Haitai is Korea's leading confectionery company that has manufactured many of the famous Korean confectioneries (See Table 1). The company was first found in 1947 as Young Il Dang Confectionary, but it has been newly established as Crown confectionery in 1968. In 2005, Crown confectionery has merged with Korea's second largest confectionery organization called Haitai, and became a holding company of Crown Haitai Holdings (https://ko.wikipedia.org/wiki/). The agency that operated this workshop was a design team of Professor Ken Nah, International Design School of Advanced Studies (IDAS), Hongik University. This academic team planned and conducted the overall contents of collaborative workshop in order to improve the creativity of employees in Crown Haitai.

Table 1 Client and Agency Overview

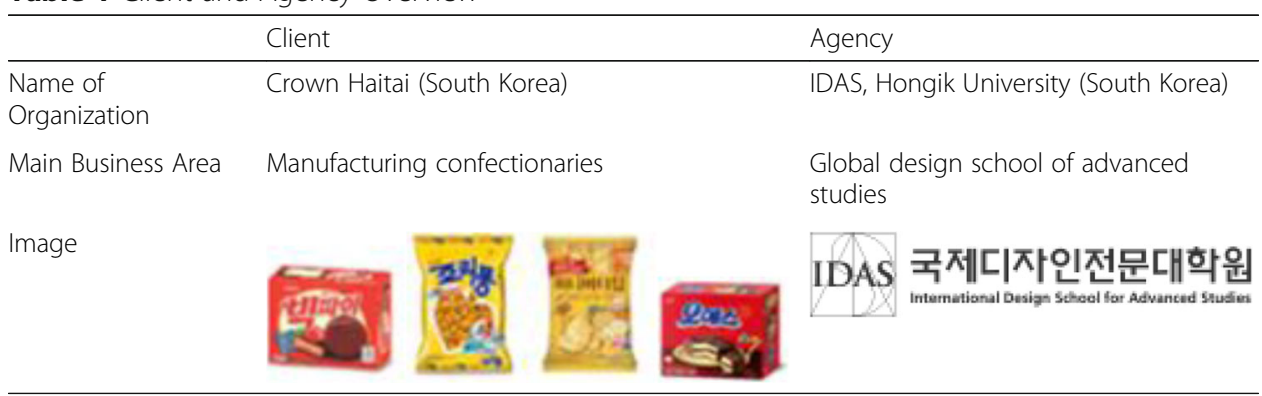

\section{Workshop background and objective}

While Crown Haitai has capabilities in manufacturing confectionaries for a long period of time, they became increasingly aware of the necessity to enhance creative thinking abilities of the employees in order to establish a breakthrough for creating innovation and to consciously improve an organizational culture. For this reason, Crown Haitai requested a workshop to the team of Professor Ken Nah with the intention of cultivating the creativity of employees, training a mindset of out-of-box thinking and developing creative ideas (See Table 2). 
Table 2 Crown Haitai Workshop Background and Objective

\begin{tabular}{ll}
\hline Categorization & Categorical Content \\
\hline Background & Awareness of employees' creative thinking abilities to create innovation for organization \\
Objective & - To cultivate the creativity of employees and to foster a mindset of out-of-box thinking \\
& - To think of creative confectionery ideas for display \\
\hline
\end{tabular}

\section{Workshop plan}

The workshop mainly conducted in approaches to creative education for employees of Crown Haitai and was designed in two stages (See Table 3).

Table 3 Workshop Plan

\begin{tabular}{lll}
\hline Categorization & Categorical content & \\
\hline Date/Time & - 1st Stage: May 15, 16, 21, 22, 23, 28, 29, June 11-13, 2013 (6 h) \\
Location & Crown Haitai's theme park of cultural arts, 'Art Valley' & \\
Participant & Client & Agency \\
Participant & Crown Haitai employees in 1st and 2nd stages & Hongik University, IDAS \\
& $\begin{array}{l}\text { (S49 people in total } \\
\text { (Salesmen, marketing team, sales planning team, }\end{array}$ & $\begin{array}{l}\text { A team of Professional Ken Nah, } \\
\text { design majors }\end{array}$ \\
& development team, branch manager) & : 9 people in total. \\
Role of & Ideate as a workshop participant & - Design a frame for workshop \\
Participant & & - Expand discussion opportunities \\
& & among participants \\
& & - Observe the patterns of direct and \\
Content & - 1st stage: Developing creativity (ideation with using clips, tangram) & indirect behavior of participants
\end{tabular}

\section{Workshop process}

In the first stage of the workshop, they involved in developing creativity and out-of-box thinking, using clips and tangrams. In the second stage, employees worked as a team to build their own creative personal displays, and the WIPR(Word, Image, Prototyping, Role-playing) process was used during the workshop. In the first stage, creative ideation of using clips and Tangram has given the certainty and opportunity to change the perception of problems and how existing ideas can be developed further into different ways of thinking. This also helped in the part of idea development on the next step. Therefore, in the process of collaborative workshop, it is necessary to lightly perform the activities of such plays that provide a positive influence to the following workshop thus, it is highly recommended (See Fig. 2).
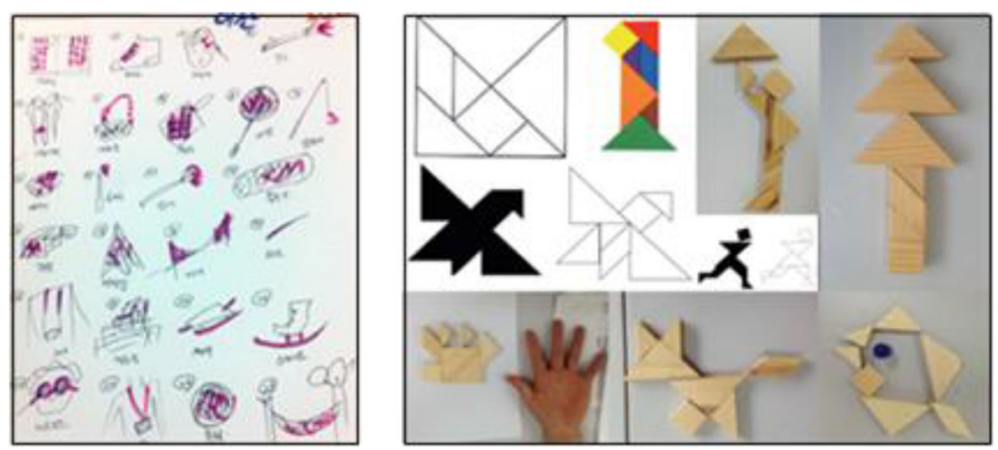

Fig. 2 Creative Ideation with Using Clips \& Tangram. Source: Hongik University, 2013 


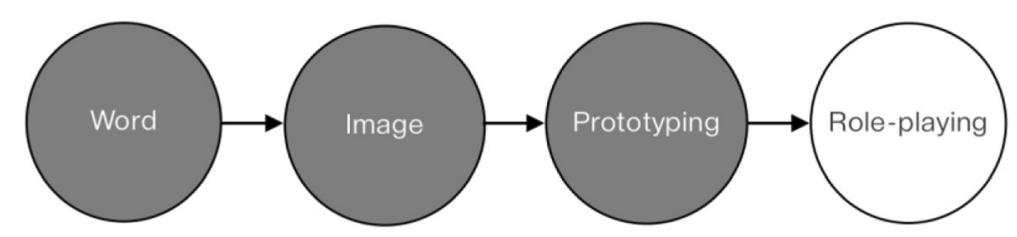

Fig. 3 WIPR Process

In the second stage, Crown Haitai employees were given a task to produce creative confectionary displays. At this point, WIPR Process was applied as the workshop progress. The WIPR (Word-Image-Prototyping-Role Playing, See Fig. 3) process designed by Ken Nah, is composed of easy handling design methods that allow participants to shape and explore the idea quickly within a team to participate in the ideation process. This process consists of Word (express in words), Image (express through pictures), Prototyping (express in creating), and Role-playing (express in actions).

- Word: Express specific idea in words through divergence and convergence thinking with a given topic.

- Image: Express through pictures drawing images of the words that are extracted from the previous phase.

- Prototyping: Express in creating 3-dimensional objects using given materials, of the specific image that was built in the second phase.

- Role-playing: Express in actions by using created objects to make and perform own stories.

In the 'Word' phase, the first step was to mind-map some of the words with team members relating to the concept of 'creative display'. Listing up words is a best way of idea generation and when it comes to the part of searching for those keywords, it also gives an opportunity to understand the differences of one's thoughts about the problem and improve one's common understandings. In the second phase, they created an image board by making a collage of visual images from ideas and keywords extracted from the previous phase. Afterwards, the idea was visualized and deliberated in a series of rough sketches. Third, in the prototyping phase, they made objects with chosen concept or idea by using given materials. In the workshop, each team has made a confectionery display by using simple materials, including sorghum straws and hardboards. Fourth, in the role-playing phase, the results attained in Word, Image and Prototyping phases are shared in front of all participants. This is an effective way to make more concrete ideas that could form a consensus of other members by storytelling and making scenarios up to stories and see how this idea could deliver to the real customers. A workshop task of making creative
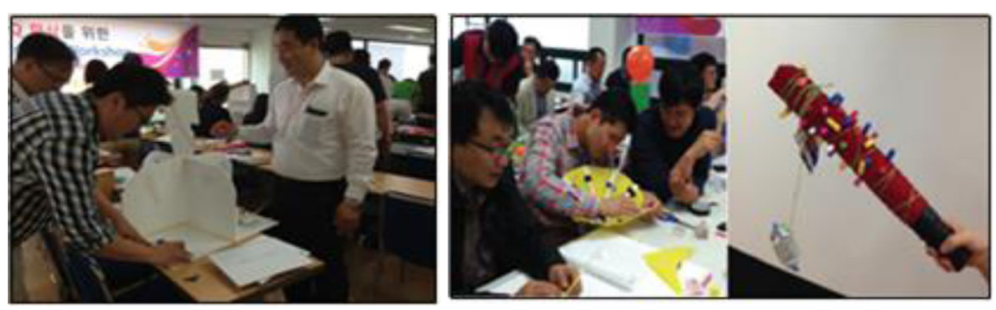

Fig. 4 Workshop Activity. Source: Hongik University Report for the Workshop 
displays was designed with the purpose of developing employees' creative side and to experience creative solving processes and design thinking with WIPR process than the intention of its actual use (See Fig. 4).

\section{Workshop results}

The outputs of each phase of the workshop have started from using words with mind mapping to image boards, to prototypes of ideas, and to presentations of a play. By looking at this each step, the idea became an increasingly sturdy and much more concrete as it visualizes through the process (See Fig. 5).

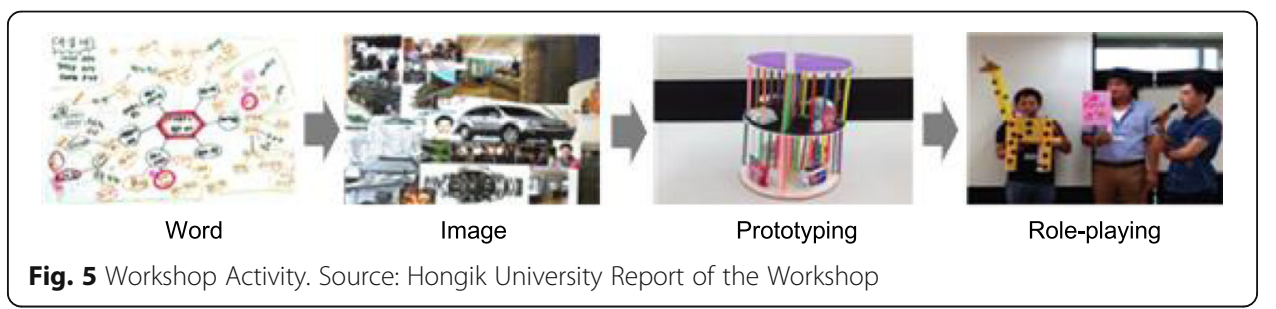

\section{Workshop effect}

At the end of the workshop, feedback was received from the participants and explored ways to utilize the results from the workshop. It was not possible to make a quantitative judgment for the level of improvement of creativity. However, an evaluation survey was distributed after the workshop and an average of 6.0 satisfaction ratings were collected out of 7.0. Referring to the feedback, participants were experienced and agreed in a fresh impact, high level of engagement, importance of communication and respect between team members, opportunity for inspiring new vitality, and a significance of creativity and differentiated competitiveness (See Table 4).

Table 4 The Feedback on the Workshop from the Participants. Source: Hongik University Report for the Workshop

- A fresh approach to workshop, high level of engagement

- Understanding the importance of communication and respect between team members

- An opportunity for inspiring vitality

- Becoming aware of the significance of creativity and differentiated competitiveness

Additionally, the outputs of creative display ideas were simulated and their suitability and adequacy will be examined within an objective framework, and planned to be utilized prudently for revitalizing sales (See Fig. 6).

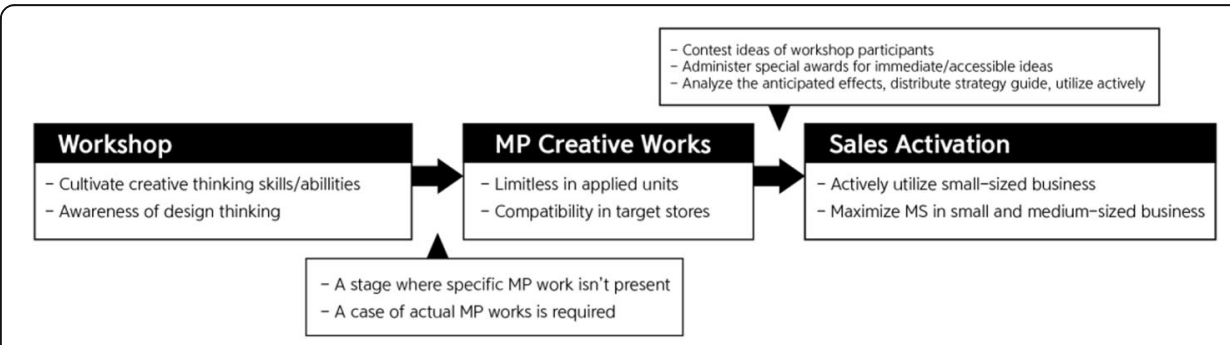

Fig. 6 Application Plan of the Collaborative Workshop for Sales Department 
ISTN

\section{Company overview}

ISTN is a specialized organization that collaborates with partners who manipulate IT solutions and provides total informatization services to other organizations (ISTN Consulting). In regard to a global partner of SAP (University of St. Gallen) (2005), and conducting the project of 'Bulk Bin Monitoring Dashboard for Feed Companies', the main business area of this organization is to build IoT sensor based ERP program and responsible for the maintenance of this program (SAP. Constructing a smart bulk bin monitoring system) (See Table 5).

Table 5 Client and Agency Overview

\begin{tabular}{lll}
\hline & Client & Agency \\
\hline Name of Organization & ISTN (ISTN Co.,Ltd.) & SAP (SAP Design, AppHaus Korea) \\
Main Business Area & $\begin{array}{l}\text { SAP ERP build and maintenance, } \\
\text { SAP 3rd solution, supply of business } \\
\text { Software (ESP) }\end{array}$ & $\begin{array}{l}\text { - Provide solutions for multinational software } \\
\text { - Provide consultation education on } \\
\text { e-commerce and software development } \\
\text { for business }\end{array}$ \\
\hline
\end{tabular}

\section{Workshop background and objective}

Companies that supply feed to livestock farms in this ecosystem are facing problems with 'low profitability of feed supply,',competitive rivalry among related companies in an industry', and 'errors in feed ordering'. Most of these problems are caused by the operating system of Bulk Bin for feed management, and in order to identify the problem more concisely, ISTN and SAP conducted a Design Thinking Workshop, including all stakeholders of the dairy industry. The background and objective of the workshop are shown as below (See Table 6).

Table 6 ISTN-SAP DT Workshop Background and Objective

\begin{tabular}{ll}
\hline Categorization & Categorical content \\
\hline Background & - Identify the causes of declining industrial competitiveness of feed suppliers, \\
& Build an effective plan of improvement \\
Objective & - Identify potential complaints of livestock farmers and dairy industry stakeholders \\
& - Find the right problems to improve the Bulk Bin Monitoring Dashboard, \\
& Determine solutions \\
\hline
\end{tabular}

\section{Workshop plan}

The workshop was structured in a three-stage process: Approach to Problems, Reframe the Problem, and Planning Future Vision based on the Experience. Prior to the beginning of the workshop, SAP (Agency) accompanied participants to basic pre-training of the Design Thinking methodology for about an hour in favor of encouraging their understanding and active engagement (See Table 7).

\section{Workshop process}

The first stage of the workshop, 'Approach to Problems' process aims to introduce issues relating to ecosystem of dairy industry among the participants of workshop and determine 
Table 7 Workshop Plan

\begin{tabular}{|c|c|c|}
\hline Categorization & Categorical content & \\
\hline Date/Time & August $21^{\text {th }}, 2015(9: 00 \mathrm{AM} \sim 6: 00 \mathrm{PM} / 8 \mathrm{~h})$ & \\
\hline Location & SAP Korea Office (Seoul) & \\
\hline Participant & Client & Agency \\
\hline Participant & $\begin{array}{l}\text { - Companies to be developed in loT solution based on } \\
\text { SAP Platform, } 6 \text { people } \\
\text { - Order Management System developer, } \\
1 \text { person - Feed producer/sales company, } 1 \text { person } \\
\text { - IOT sensor link developer, } 1 \text { person } \\
\text { - SAP loT experts, platform service provider, } \\
\text { partnership manager, } 4 \text { people } \\
\text { - Farmer, } 1 \text { person: } 14 \text { people in total }\end{array}$ & $\begin{array}{l}\text { - Project manager, } 1 \text { person } \\
\text { - Design thinking expert, } 2 \text { people } \\
\text { - UX designer, } 1 \text { person } \\
: 4 \text { people in total }\end{array}$ \\
\hline $\begin{array}{l}\text { Role of } \\
\text { Participant }\end{array}$ & $\begin{array}{l}\text { - Provide work difficulties and requirements } \\
\text { - State alternatives and opinions }\end{array}$ & $\begin{array}{l}\text { - Design a frame for workshop } \\
\text { - Expand discussion opportunities } \\
\text { among participants } \\
\text { - Observe the patterns of direct and } \\
\text { indirect behavior of participants } \\
\text { - Induce field-oriented feedback }\end{array}$ \\
\hline Content & \multicolumn{2}{|c|}{$\begin{array}{l}\text { - Visualize ecosystem of dairy industry using SAP 'Scenes' storyboard tool and pictogram too } \\
\text { - Plan process map of loT based Kick-starter } \\
\text { - Offer New Business idea }\end{array}$} \\
\hline
\end{tabular}

the nature and scope of common problems through finding the context of other participants. Thereupon, all stakeholders started off to briefly describe key pending issues regarding their own work. In this process, participants appreciated the whole ecological environment of the dairy industry that they had not realized before, and noted the difficulties that other participants experienced in their work. At that moment, the workshop host (SAP) coordinated participants' comments and created an atmosphere for discussion where they could focus on the contents of each speaker. In the second stage, 'Reframe the Problem, they focused on finding interrelationships among stakeholders and from this, they obtained insights of the right problem solving. In this context, participants analyzed the value chain of the dairy industry by using visual tools, such as SAP 'Scenes' storyboard tool and pictogram to visualize their proposal ideas. After analyzing these visualized pending issues, participants concurrently started to plan for process map of IoT based Kickstarter. In the third stage, 'Planning Future Vision based on the Experience', participants suggested not only to the solutions of common problems but also additional solutions of extend problems they discovered (See Figs. 7 and 8).

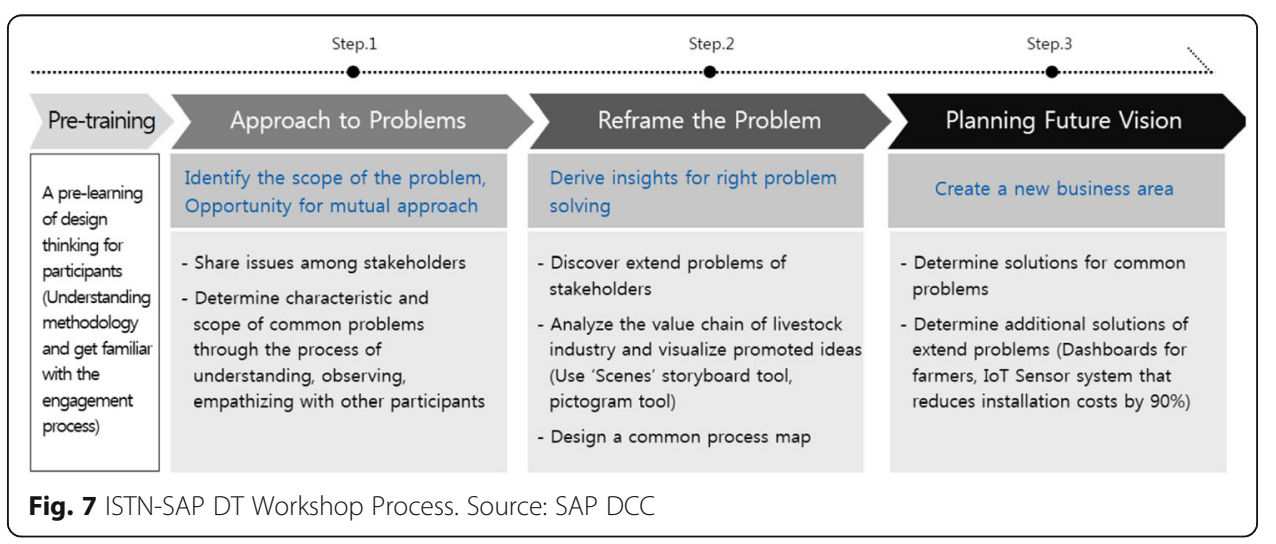




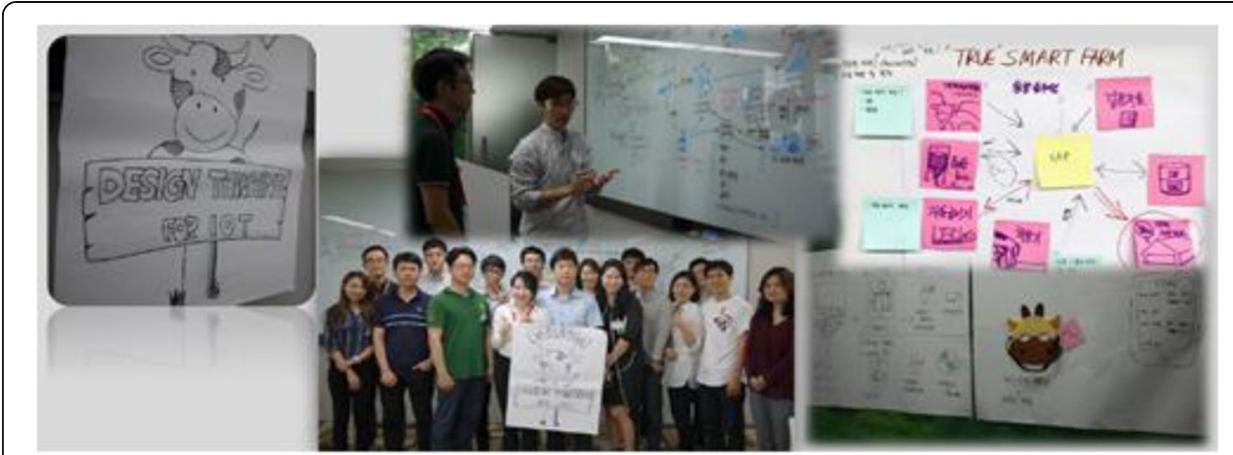

Fig. 8 Workshop Activity. Source: SAP DCC

\section{Workshop results}

The result of the workshop is divided into two aspects. First, it is a redefinition of the right problem that feed suppliers and livestock farms may potentially have. The problems of feed suppliers were to discover the dissatisfaction of the livestock farmers. Such problems were fundamentally happened as errors on the part of ordering from telephone calls. The details are shown below in Fig. 9.

\begin{tabular}{|l|l|}
\hline \begin{tabular}{l} 
The right problem of livestock farms \\
\hline $\begin{array}{l}\text { Ordering feed by phone } \\
\text { - Product code of ordered feed is unclear }\end{array}$ \\
- Quantity of ordered feed is inaccurate
\end{tabular} & $\begin{array}{l}\text { The right problem of feed suppliers } \\
\text { profitability of feed suppliers due to } \\
\text { errors in feed ordering }\end{array}$ \\
\hline $\begin{array}{l}\text { Difficult to find remaining feed due to } \\
\text { inaccuracy of bulk bin and high amount } \\
\text { of sensor installation }\end{array}$ & $\begin{array}{l}\text { Difficult to manage customer of existing sensor } \\
- \text { More than } 1,2000 \text { customers order feed } \\
\text { - A number of nationally managed bulk bin } \\
\text { emerge more than 100,000. }\end{array}$ \\
\hline
\end{tabular}

Second, leveraging insight is a solution to solve the redefined right problem. The solution to the right problem through workshop was proposed based on collaboration with IoT, including GEOIZE, JCSquare, SAP Solution Center to improve existing ERP and the bulk bin. A proposed solution is shown below in Fig. 10.

\section{Workshop effect}

This workshop supports to develop plans for stable feed production by proposing a 'Smart Bulk Bin Monitoring Idea', which enables feed suppliers to identify the real-time feed production, sales, and inventory status. The experimental model of Smart Bulk Bin Monitor Dashboard for feed suppliers and livestock farmers is shown in Figs. 11, 12, 13 and 14. The smart Bulk Bin connected with SAP HANA IoT sensor data will track the amount of feed residues and provide farmers with accuracy of feed ordering and enable feed delivery in a timely manner. This is expected to ultimately improve the quality of 


\begin{tabular}{|c|c|c|c|}
\hline Existing ERP of feed suppliers & Improved ERP of feed suppliers & & \\
\hline $\begin{array}{l}\text { - Diversification in ordering } \\
\text { communication channels } \\
\text { (web, mobile) } \\
\text { - Order history, shipment history, } \\
\text { account ledger inquiry }\end{array}$ & $\begin{array}{l}\text { - Diversification in ordering communication } \\
\text { channels (web, mobile) } \\
\text { - Order history, shipment history, account } \\
\text { ledger inquiry } \\
\text { - Provide estimates of remaining amount of } \\
\text { bulk bin }\end{array}$ & & \\
\hline $\begin{array}{l}\text { Existing bulk bin of feed } \\
\text { suppliers }\end{array}$ & Improved bulk bin of feed suppliers & & Cooperating company \\
\hline $\begin{array}{l}\text { Afford the cost of sensor } \\
\text { installation }\end{array}$ & $\begin{array}{l}-90 \% \text { cost reduction in sensor : make a } \\
\text { reasonable price } \\
\text {-Develop sensor, supply farms } \\
\text {-Data transmission through central network } \\
\text {-Install cover for bulk bin prevention }\end{array}$ & ঊ. & $\begin{array}{l}\text { GEOIZE (Design process) } \\
\text { JCSquare (Develop IoT Sensor, build } \\
\text { communication module) } \\
\text { ISTN (Comm. Layer (Design HANA DB, } \\
\text { Develop UX) } \\
\text { SAP (Provide HCP HANA Cloud } \\
\text { Platform) }\end{array}$ \\
\hline
\end{tabular}

Fig. 10 Workshop Results 2. Source: SAP DCC

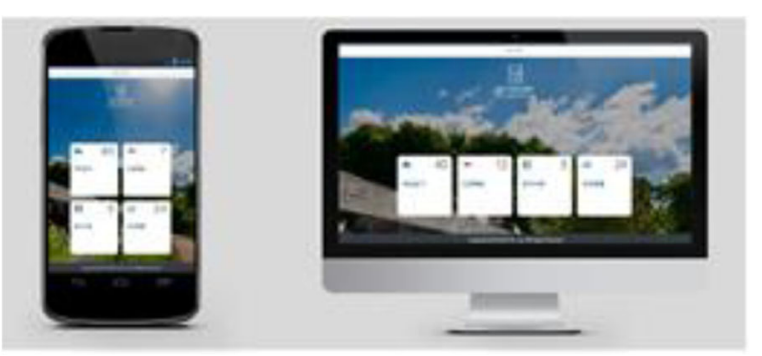

Fig. 11 A Main Display of Bulk Bin Monitor for Feed Companies

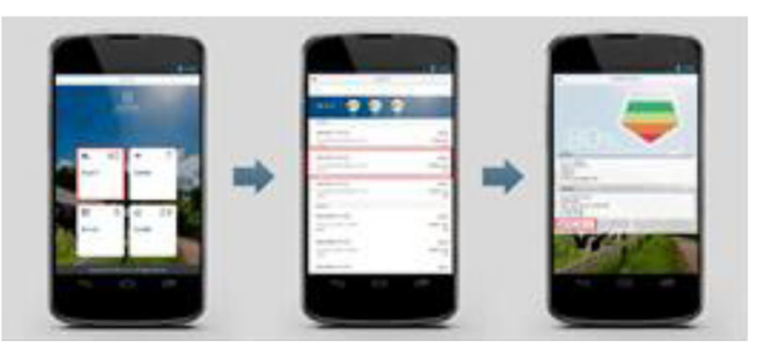

Fig. 12 Bin Information of Livestock Farmers and Other Farmers

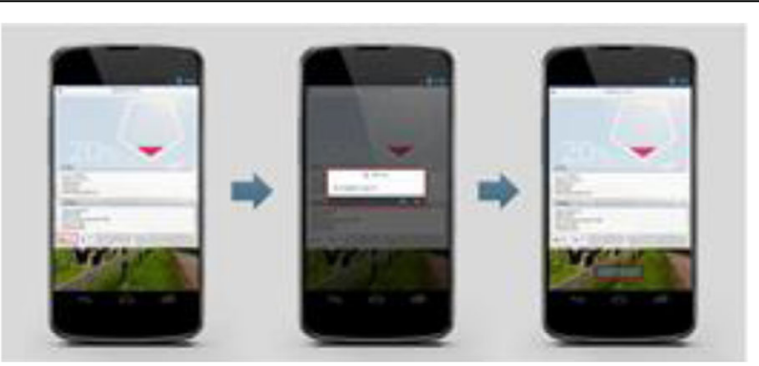

Fig. 13 Bin Information of Livestock Farmers/Other Farmers: filtering functions 


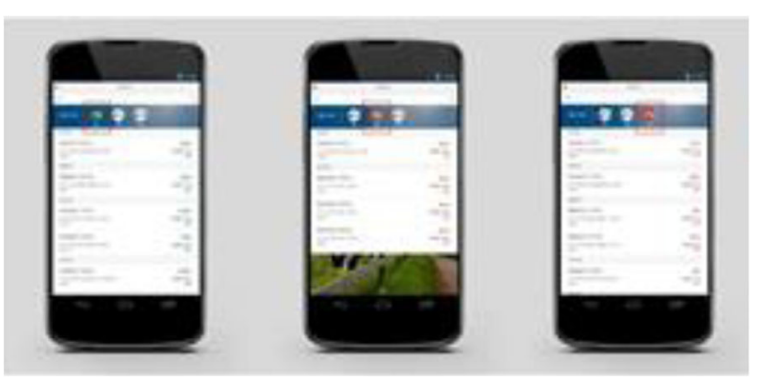

Fig. 14 Shipping Instructions on Fast-Delivery List of Bin

feed and feed suppliers. Additionally, an Electronic Approval System named, iFLOW will be introduced as a new business area, and the delivery status of feed and tracking of the Credit Check Process will get accessible. Another significance of the workshop is that various members of the dairy industry with different fields of discipline, including IoT sensor support company, ERP builder, ISTN and SAP's SAP Solution Center and IoT $\mathrm{T} / \mathrm{F}$ have worked together to broaden the understanding of design thinking process and determine the scope of the right problem. Such process is anticipated to encourage direct and indirect stakeholders and clients to present a new thinking paradigm in approaching and solving problems, thus expanding a practical prototyping culture in approach to the problems of organization or industrial ecosystem in the future.

\section{Museum san}

\section{Company overview}

While renewing the brand of Museum San, a collaborative workshop was held with museum authorities and professionals with brand expertise from Interbrand, the global branding agency. The company's creative workshop was aimed at leveraging the inherent diversity of thoughts and ideas and to come up with many ideas in a short period of time. Interbrand assigned a collaborative workshop with staff of the client, the Hansol Museum, to set the direction for the new brand, position and value. The workshop was conducted into two steps; find keywords and visualize through images and sketches (See Table 8).

Table 8 Client and Agency Overview

\begin{tabular}{lll}
\hline & Client & Agency \\
\hline Name of Organization & Hansol Cultural Foundation & Interbrand Seoul \\
Main Business Area & $\begin{array}{l}\text { Art Museum } \\
\text { (Located in Wonju, Gangwondo) }\end{array}$ & \\
Representative Images &
\end{tabular}




\section{Workshop background and objective}

The objective was to change the former brand name of Hansol Museum to Museum San and its visual systems. Concerning that the museum is located in the mountains and its unique characteristics of architecture eventually did not reflect the image that the museum wanted, therefore, further adjustments were needed in change of the name and design. A development on symbolic museum naming and visual systems were required, pertaining its own geographical and emotional characteristics and to have intention point without using the parent company's name of 'Hansol'. They needed a way to effectively establish the brand development and get ideas in the early stage of the project (See Table 9).

Table 9 Hansol Museum Workshop Background and Objective

\begin{tabular}{ll}
\hline Category & Categorical Content \\
\hline Background & $\begin{array}{l}\text { A brand renewal in name and design system of Hansol Museum is } \\
\text { needed by reflecting on the image of surrounding environments } \\
\text { and the image that museum pursues. } \\
\text { Objective }\end{array}$ \\
\hline
\end{tabular}

\section{Workshop plan}

The workshop was held on November 14th, 2013, in the seminar room of the museum for almost half of the day. The workshop is organized as follows (See Table 10).

Table 10 Museum Workshop Plan

\begin{tabular}{lll}
\hline Categorization & Categorical Content & \\
\hline Date/Time & November 14th, 2013 (4 h) & \\
Location & Hansol Museum Welcome seminar room & \\
Participant & Client & Agency \\
Participant & Hansol Cultural Foundation 8 museum & Interbrand 8 people \\
& practitioners & (verbalists, designers, brand \\
Role of & Idea generation & strategists) \\
Participant & & - Design a frame for workshop \\
& & - Expand discussion opportunities \\
& & among participants \\
& & - Observe the patterns of direct and \\
Indicate a new brand naming for museum, set directions of the design and generate ideas
\end{tabular}

\section{Workshop process}

Teamwork activities were divided into two sessions and conducted with word and image. In consequence, they were allowed to share the results to the whole group (See Fig. 15).

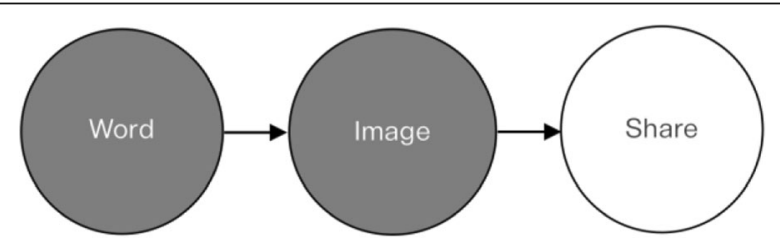

Fig. 15 Museum San Workshop Process 
First, in the word session, each team was asked to select three words that could describe the new museum among a set of two keywords - functional words and emotional words. Based on this activity, the first session was finished by pondering and developing new names for the museum. Second, in the image session, images from a magazine were collaged that reminiscently represents the image of the museum, and new visual symbols of museum were created. In this context, participants defined their own character of the museum and subsequently, they started to think of ideas for symbols of the museum (See Fig. 16).

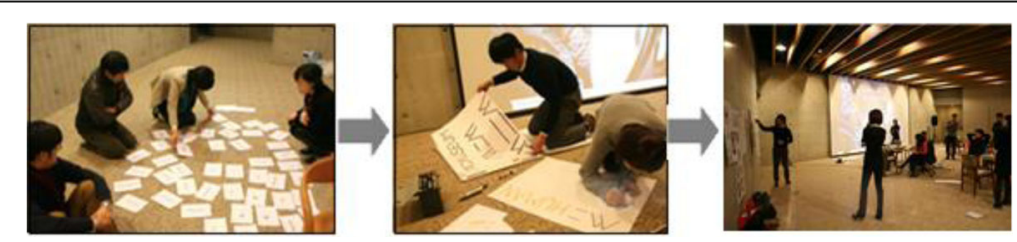

Fig. 16 Museum San Workshop Activity

\section{Workshop results}

The results of the two sessions were the keywords and images of each team's outputs of the activities. The most outstanding keywords were mountain and architectural features. Keywords such as nature, light, mountain, meditation were dominant from the image and sketch session (See Fig. 17).

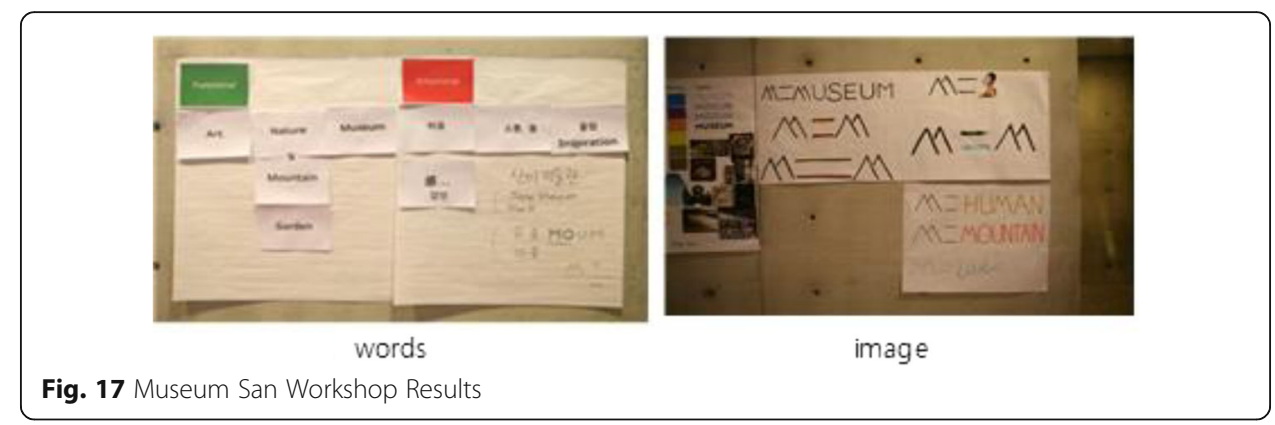

\section{Workshop effect}

In the final result of the workshop, interviews with other experts were conducted and brand experts set the direction of the brand at last. A naming idea was further developed by a verbal expert, and finally named it as Museum San. The design of Fig. 18 was lastly settled with design experts. Their desire to express Korean design features, and some of the ideas and keywords like 'mountain' and 'meditation' from the workshop were reflected to the final result. The shape of the symbol of a layered mountain reflected in water gives a subtle and mysterious image of Korea's traditional technique of ink painting. It delivers the sense of how visitors of the museum are surrounded by a beauty of natural environment and unique architecture where they could relax and be emotionally stimulated (See Fig. 18). 


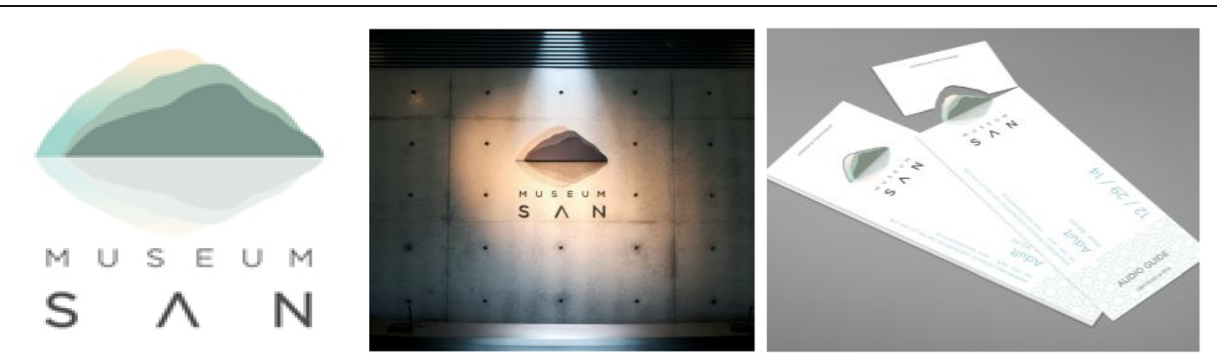

Fig. 18 Museum San Final Design

\section{Result and discussion}

Workshop case analysis

The contents of three workshops are summarized in the following Table 11.

Table 11 Workshop Case Summary

\begin{tabular}{|c|c|c|c|}
\hline & Crown Haitai & ISTN & Museum San \\
\hline Background & $\begin{array}{l}\text { Awareness of employees' } \\
\text { creative thinking abilities to } \\
\text { create innovation for } \\
\text { organization }\end{array}$ & $\begin{array}{l}\text { Identify the causes of declining } \\
\text { industrial competitiveness of } \\
\text { feed suppliers, Build an effective } \\
\text { plan of improvement }\end{array}$ & $\begin{array}{l}\text { A brand renewal in name and } \\
\text { design system of Hansol Museum } \\
\text { is needed by reflecting on the } \\
\text { image of surrounding } \\
\text { environments and the image that } \\
\text { museum pursues. }\end{array}$ \\
\hline Objective & $\begin{array}{l}\text { To cultivate the creativity of } \\
\text { employees and to foster a } \\
\text { mindset of out-of-box } \\
\text { thinking }\end{array}$ & $\begin{array}{l}\text { Identify potential complaints of } \\
\text { livestock farmers and dairy } \\
\text { industry stakeholders } \\
\text { - Find the right problems to } \\
\text { improve the Bulk Bin } \\
\text { Monitoring Dashboard, } \\
\text { Determine solutions }\end{array}$ & $\begin{array}{l}\text { Deriving ideas for naming and } \\
\text { logo design and set directionality } \\
\text { of the brand regarding museum }\end{array}$ \\
\hline Process & WIPR process & $\begin{array}{l}\text { Approach to problems -> } \\
\text { Reframe the problem - > } \\
\text { Planning Future Vision }\end{array}$ & Keywords-> Image- > Sharing \\
\hline $\begin{array}{l}\text { Result and } \\
\text { Effect }\end{array}$ & $\begin{array}{l}\text {-Received positive feedback } \\
\text { on improvement of } \\
\text { creativity } \\
\text {-Establish plans on utilizing } \\
\text { ideas of creative display }\end{array}$ & $\begin{array}{l}\text { - 90\% cost reduction in sensor: } \\
\text { make a reasonable price } \\
\text {-Develop sensor, supply farms } \\
\text {-Data transmission through } \\
\text { central network } \\
\text {-Install cover for bulk bin } \\
\text { prevention }\end{array}$ & $\begin{array}{l}\text {-Environment and emotional } \\
\text { image of the museum is } \\
\text { reflected in the final result }\end{array}$ \\
\hline
\end{tabular}

The analysis of the overall distribution of cases shows some aspects about the significance and effectiveness of the collaborative workshop. Each case was manipulated with different backgrounds and objectives, however, the result of each workshop has common features that they all have this unraveling process of visualizing, discussing and expressing inherent ideas, despite the fact that the output of each workshop had different perspectives appearing within team members and individuals. In the development of innovative problem solving, collaborative workshop implies the importance of mutual understanding and communication been the client and agency as lateral/collaborative partners. It can also form a consensus within groups of face-to-face problems and formulate a basis in the revelation of collective intelligence. And it can encourage the improvement of practical prototyping culture approaching problems within organizations. 


\section{Workshop process comparative analysis}

Some common elements were discovered in the process of these three workshops while each one of them had different backgrounds and objectives, ergo this study aimed at comparing and analyzing those of the processes in more specific details. The processes of three workshops can be categorized into four steps. The first step is to approach toward defining and analyzing problems by selecting words. The second step is to ideate through an image or a sketch. The third step is to quickly test the ideas and identify the likely directions for problem solving from prototyping. The fourth step is to share ideas and directions by role-playing or presenting to the entire group (See Table 12).

Table 12 Collaborative Workshop Process Comparative Analysis

\begin{tabular}{|c|c|c|c|c|}
\hline Workshop Case & Process & & & \\
\hline Crown Haitai & Word & Image & Prototyping & Role-playing \\
\hline ISTN & $\begin{array}{l}\text { Approach to problem } \\
\text { Redefine the problem }\end{array}$ & & Planning Future vision & \\
\hline Museum San & Keywords \& Naming & Image \& Sketch & & Sharing \\
\hline
\end{tabular}

In order to understand the process and its effects in collaborative workshops, a set of keywords that can describe all the behaviors and objectives in the process of three workshops are discovered. This can be compiled into four categories - enhancing common understanding, accelerating ideation, rapid testing, and sharing direction (See Table 13).

Table 13 Keyword Categorization of the Collaborative Workshop Process

\begin{tabular}{|c|c|c|c|c|}
\hline Process keyword & Crown Haitai & ISTN & Museum San & Categorization \\
\hline Shared Issues & & $\bullet$ & & Enhancing common understanding \\
\hline Approach to problem & & $\bullet$ & & Enhancing common understanding \\
\hline Redefine the problem & $\bullet$ & $\bullet$ & $\bullet$ & Enhancing common understanding \\
\hline Select keywords & $\bullet$ & & & Enhancing common understanding \\
\hline Select Images & $\bullet$ & $\bullet$ & $\bullet$ & Accelerating ideation \\
\hline Sketch & $\bullet$ & $\bullet$ & $\bullet$ & Accelerating ideation \\
\hline Making up Scenario (SAP Scences) & & $\bullet$ & & Accelerating ideation \\
\hline Pictogram Tool & & $\bullet$ & & Accelerating ideation \\
\hline Prototyping & $\bullet$ & $\bullet$ & $\bullet$ & Rapid testing \\
\hline Role-playing & $\bullet$ & $\bullet$ & & Rapid testing \\
\hline Presentation & $\bullet$ & $\bullet$ & $\bullet$ & \\
\hline Develop the Co-Process Map & & $\bullet$ & & Sharing Direction \\
\hline Planning Future Vision & & $\bullet$ & & \\
\hline
\end{tabular}

The process keywords in the leftmost column are the words that list all the processes in each collaborative workshop of the three companies, and they are checked with a circle icon $(\bullet)$ in the process keyword corresponding to each workshop. Each process is grouped into several categories and marked on the right categorization

The contents of each category for classification are indeed yields throughout the workshop. For instance, all the processes of finding words, collaging images, making prototypes and presenting outputs to other teams will share their inherent ideas and improve interaction and build a common understanding among different organizations. Nonetheless, there were representative purposes and activities in each stage of the workshop. In other 
words, the improvement of common understanding is fixed in all the processes of selecting keywords, sketching, prototyping and sharing through presentations in the workshop, yet as a basis for solving organizational problems, access of problems to have a common understanding together is done in the very early stage of the workshop.

\section{Collaborative workshop model}

Based on the research, collaborative workshop can be managed through a variety of issues and objectives under multiple circumstances of client organization. For instance, having design ideas during the early part of the project can be a major purpose of the collaborative workshop. SAP, for instance, manages access to clients through design thinking oriented workshops. They carry collaborative workshops through gathering executives from client organization and determine their problems to find solutions, or they use design-thinking tools to train creative thinking skills to new employees. Depending on the circumstances, the client and agency can forge ahead a collaborative workshop accommodating multiple interests. In this way, collaborative workshop can be carried through a variety of purposes and issues involving clients, agencies or other stakeholders, but at the same time, all the collaborative workshops have a common purpose. There are common aspects to be gained from the client's point of view and from the agency's point of view in collaborative workshop. There are four purposes in the collaborative workshop.

The first purpose is to develop a common understanding. Collaborative workshops define design issues between client and agency and enhance their common understanding. This gives an opportunity for agency to understand the client's thoughts about the project. With regard to common understanding, communication between the client and agency will be well facilitated in the design process. Second, it is to accelerate ideation process. It is necessary to expand as many ideas as possible from the collaborative workshop. Open innovation is a collaborative workshop where various stakeholders come together to look at problems from multiple perspectives, thus a variety of solutions can be found. Also one's idea can add up to another idea or provide feedback to inspire each other. Third, another purpose of collaborative workshop is to make a quick test. In the collaborative workshop, possibility of ideas can be testable through visualizing ideas such as images, sketches, creating prototypes of three dimensional objects and so on. This will help in identifying the need of verifying, revising, developing or making new ideas. Lastly, it is to share direction among stakeholders. In the collaborative workshop, client and agency can set the directionality of their outputs at first. Thus, it is advantage for agency to share risks with client before the design output releases. These four purposes can be achievable through collaborative workshops. Hence, the workshops should be well organized to achieve the purposes when it comes to planning the process of collaborative workshop. It is necessary to concisely follow through each step at each category of the workshop. So the workshop includes the process of achieving each purpose, in which four purposes of the collaborative workshop are - enhancing common understanding, accelerating ideation, rapid testing, and sharing direction. Four purposes are made through the workshop process. And four steps of the category can be partially shaped through the workshop. For instance, accelerating ideation can be carried during the prototyping process for a quick test as 
well as making an image collage. By focusing on each purpose, the four objectives can be effectively achieved.

A wide variety of tools can be applied depending on the differences of the results gained from the workshop. Such tools can be also used to revitalize ideation or increase the efficiency of the workshop depending on the characteristics or cultural backgrounds of the participants. For instance, most people in Korea are more likely to brainstorm and ideate individually than with team members as they avoid to express themselves in front of people, thus by taking brain writing methods could gather and reflect individual ideas. Although there may be differences in details of the process or tools applied, the collaborative workshop should undergo these four stages. This is a participatory design called design thinking, based on efficient design methodology through rapid prototyping, and an open innovation method that creates synergy beyond the relationship between existing client and agency. Generally, workshop is conducted in the order of enhancing common understanding, to accelerating ideation, to rapid testing, then to directional sharing. Through this process, workshop session would then be conducted. Yet, if the workshop did not come up in ways that yield the desired results, this process could be repeated as well. Thus, the process of collaborative workshop is cyclical and adaptive as shown in Fig. 19.

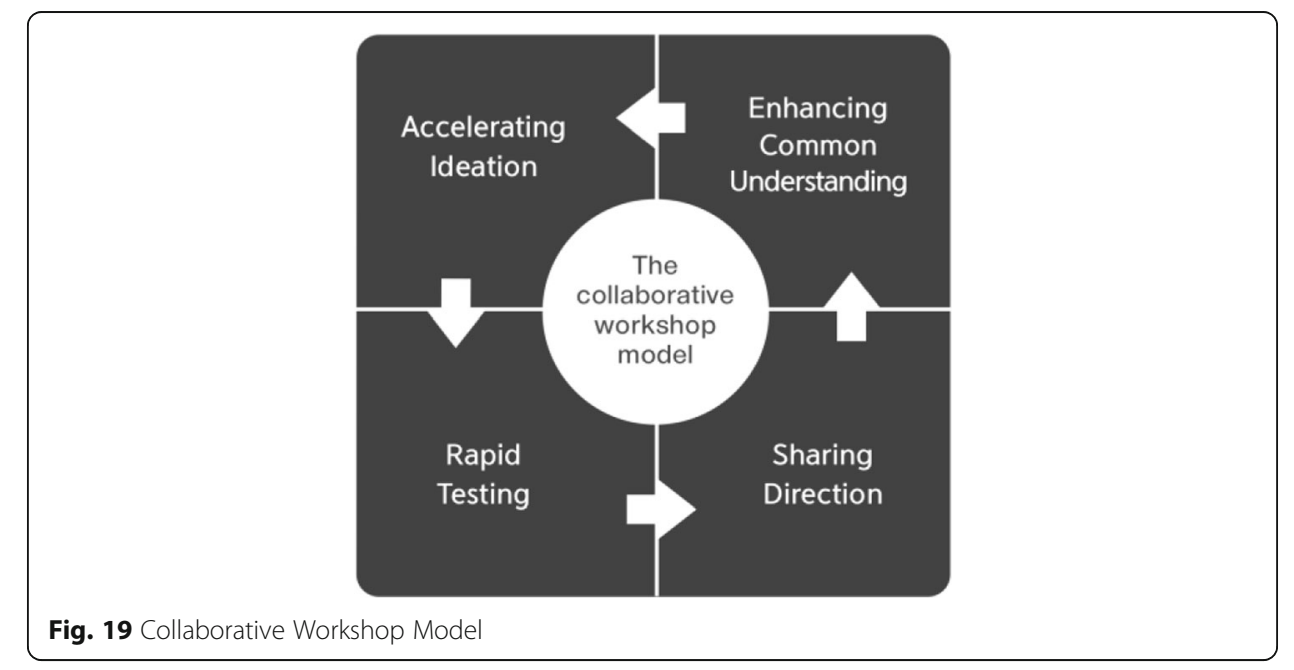

Role of client and agency in the workshop

A new relationship has formed between client and agency. As shown in the left side of the Fig. 20, by the time when collaborative workshop between client and agency was inaccessible, while client makes request to agency, agency had to take full responsibility for deriving new ideas and present them back to client. Such process can be specified as a closed innovation system. Yet in an open innovation, collaborative workshop transforms client and agency into co-working, and they engage together to conduct an ideation session and accept responsibility for outcome. During collaborative workshop, agency normally participates in the ideation process with client, though they also serve as a facilitator to intrigue 
and lead client's inherent ideas. In the closed innovation system, client was an applicant and agency was a respondent, yet in the open innovation system, both client and agency are developing ideas through collaborative workshop. Being as a co-creator, they become partners for creating innovation. The role of client and agency: co-creation, agency being as a facilitator and plays a role in bringing out client's inherent thoughts. In consequence, by extracting a lot of client's inherent thoughts and understand them would help in setting the directionality of design as it comes to the finalization of the design outcome by agency (See Figs. 20 and 21).
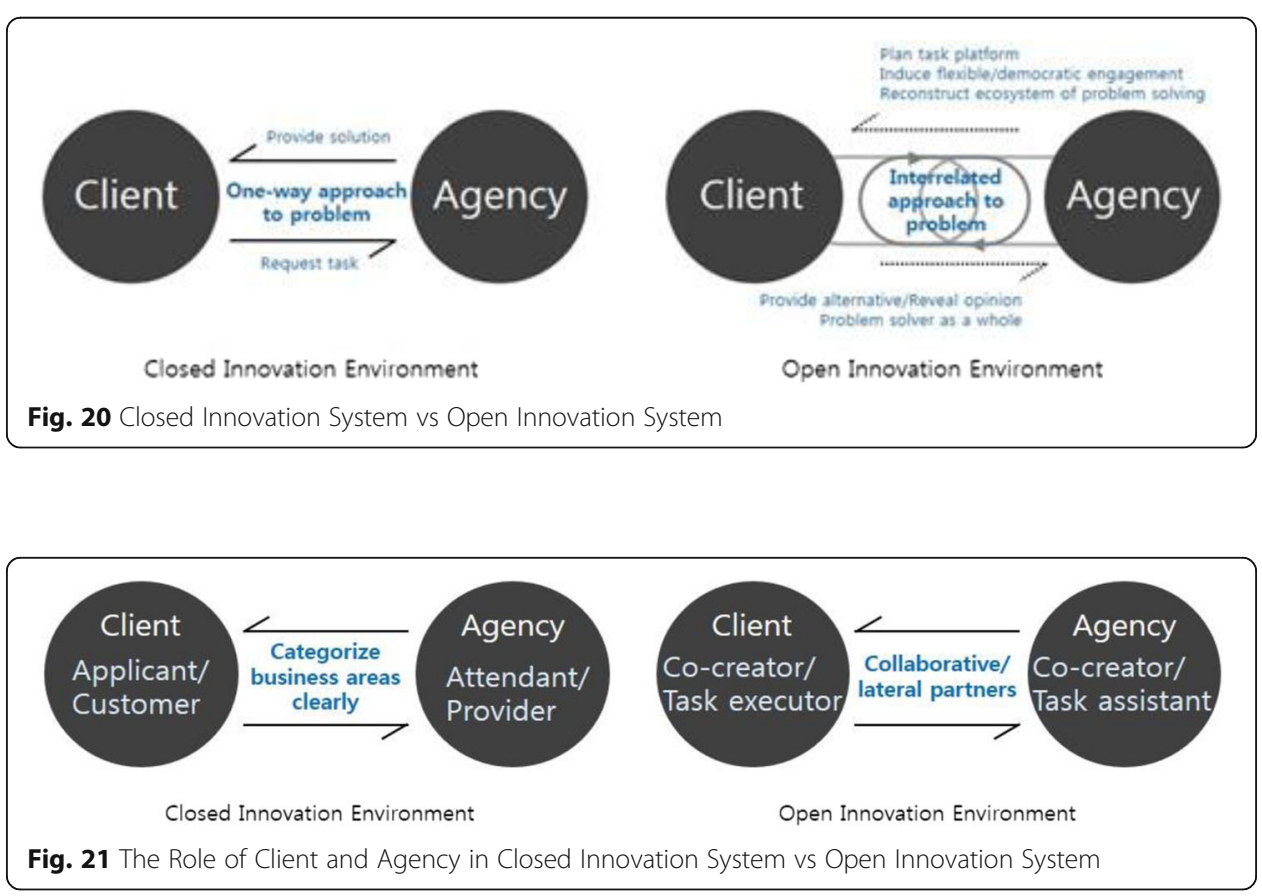

\section{Effect of collaborative workshop}

Combining the effects of collaborative workshop between client and agency through literature reviews and case studies, it concludes in co-creation as a key factor. The detailed descriptions are as follows.

First, collaborative workshop between client and agency enhances facing problems and common understanding of the projects. Collaborative workshop serves as an effective communication tool. Communication between agency and client becomes apparent in the design problems. Keeping communication smooth and straightforward improves common understanding, and as common understanding improves it makes design project more smoothly. Second, collaborative workshop between client and agency develops multiple ways of looking at problems and derives more useful problem solutions through extended idea generation. As SAP shown in the case of ISTN, a variety of stakeholders gather on identifying one single problem to redefine it to the right problem and find clear solutions to discover additional business areas. Third, co-creation can develop problem-solving ideas into a better condition through the process of converging and diverging of various ideas. The 
ideas of sharing with others promote ideas that encourage another divergent of ideas to others. Fourth, collaborative workshop between client and agency enables to verify the practicality within real-life by rapid testing. The iterative process of quickly creating ideas into an experimental model to rapidly testing and modifying in real-life circumstances is more efficient than spending time on pre-planning to discover problems. Fifth, collaborative workshop between client and agency enables co-creation and co-validation to minimize the risk of failure in the results. In the existing closed innovation system, agency became highly responsible for the results. Yet, collaborative workshop forms a common consensus in the whole process of seeking solutions because it shares the perception of crisis in problems and directionality of solutions in direct communications with client and communion. In the workshop, clients are more likely to understand the results or finding keywords, thus client's satisfaction would increase. Last but not least, there is a favorable result from agency's point of view. The agency is able to operate its products or services to clients easily. As seen in the example of SAP, it is easily adaptable to see what solution is needed for client in regard to sharing and communicating about solutions in the workshop.

\section{Conclusion}

This study introduced a collaborative workshop model. The model showed the purpose and process of the collaborative workshop. It can be applied to ideation process to make synergy between client and agency. The model was developed by analyzing three case studies. The analysis revealed the workshop not only encouraged the lively collaboration but also changed the role of client and agency as co-creators.

The significance of this collaborative workshop to open innovation can be summarized into three aspects as follows. The significance of this collaborative workshop to open innovation can be summarized into three aspects as follow. First, collaborative workshop is an effective communication tool. Client and agency can have a common understanding on their problems by doing the workshop. Client and agency can externalize their internal thoughts from each part and share ideas from different points of view. Second, collaborative workshop is an effective co-ideation tool that can create a synergy. Form collaborative workshops, companies can create diverse and better ideas through collective intelligence. Third, collaborative workshop is an effective collaboration tool. Client and agency can not only share future direction of their problem but also share risks of their outcomes. Since client would participate in ideation and setting future directions, client satisfaction of the outcome would increase. So it is efficient in ways in which it is less likely to return to the new idea stage after evaluating the result of design. It will lead to the re-establishment of the role of client and agency.

The collaborative workshop model suggested here still have much room for development and some detail could be more precisely developed with more consideration. The case study is not enough to generalize as there is not enough number of cases. This study did not measure the effect of collaborative workshop with the open innovation on actual market sales or promotion effects. Through additional research, this model should be developed and validated. 
If we add concrete research topics from this study, they are as follows. First, statistical analysis of performance of collaborative workshop will show concrete evidence of the workshop model. Second, case study of collaborative workshops in one specific business can give us a chance to understand some other insight about collaborative workshop. Third, collaborative workshop with multiple stakeholders such as producers, wholesalers, and end-users will give more implications for open innovation.

But the findings of the research still give beneficial implications for successful collaboration and the collaborative workshop model can be applied as a basis for workshop process and its effectiveness for various business issue.

Acknowledgements

This work is supported by BK21 plus. This paper was received 'best paper award' at SOltmC 2017 conference.

\section{Authors' contributions}

HJC carried out the workshop and open innovation studies and drafted the manuscript. YOJ carried out the case study. HRP contributed on the research on one of our case study, SAP. KN made a structure of the manuscript and supervised the whole study as a correspondent. All authors read and approved the final manuscript.

\section{Competing interests}

The authors declare that they have no competing interests.

\section{Publisher's Note}

Springer Nature remains neutral with regard to jurisdictional claims in published maps and institutional affiliations.

Received: 9 November 2017 Accepted: 15 January 2018

Published online: 10 April 2018

\section{References}

Beard, F. (1996). Integrated marketing communications: New role expectations and performance issues in the client-ad agency relationship. Journal of Business Research, 37(3).

Brown, T. \& Wyatt, J., (2010). 'Design thinking for social innovation', Stanford Social Innovation Review, winter. Chesbrough, H. (2003). Open innovation: The new imperative for creating and profiting from technology. Boston: MA: MBS. Gibson, B. (2016). Five tips for better client-agency collaboration. http://www.liquidagency.com/brand-exchange/fivetips-for-better-agency-collaboration/. Accessed 25 Oct 2016.

ISTN Consulting. http://www.istn.co.kr/index.php. Accessed 30 Oct 2016.

Jung, E. J., et al. (2015). 'Quantity Yields Quality When It Comes to Creativity: A Brain and Behavioral Test of the Equal-odds Rule'. https://www.frontiersin.org/articles/10.3389/fpsyg.2015.00864/full. https://doi.org/10.3389/fpsyg.2015.00864.

Kim, S. A., Ryoo, H. Y., \& Ahn, H. J. (2017). Student customized creative education model based on open innovation. Journal of Open Innovation: Technology, Market, and Complexity, 3, 6

Kodama, F., \& Shibata, T. (2015). Demand articulation in the open-innovation paradigm. Journal of Open Innovation: Technology, Market, and Complexity, 1, 2.

Kolko, J., (2015). 「exposing the magic of design: A Practitioner's guide to the Methods \& Theory of synthesis」, New York; Oxford University Press.

Lee, S. H., Workman, E. J., \& Jung, K. H. (2016). Brand relationships and risk: Influence of risk avoidance and gender on brand consumption. Journal of Open Innovation: Technology, Market, and Complexity, 2, 14.

Martin, R. (2009). The Design of Business: Why design thinking is the next competitive advantage」, Boston, Massachusetts. Harvard Business School Press.

Merriam-webster Dictionary. https://www.merriam-webster.com/dictionary. Accessed 5 Sept 2016.

Nah, K., (2017). 「design innovation note」, Seoul; Culture Code.

Nho, H. J. (2016). Research ethics education in Korea for overcoming culture and value system Differences. Journal of Open Innovation: Technology, Market, and Complexity, 2(1), 3-4.

Osborn, A., (2007). 「your creative power」, Myers press.

SAP. Constructing a smart bulk bin monitoring system. https:/experience.sap.com/designservices/work/project/ constructing-a-smart-bulk-bin-monitoring-system. Accessed 25 Oct 2016.

SAP. https://www.sap.com/corporate/en.html. Accessed 30 Oct 2016.

Shaw, M. (2016). The need for agency and client collaboration. https://www.towermarketing.net/blog/the-need-foragency-and-client-collaboration/. Accessed 10 Nov 2016.

Terwiesch, C., \& Loch, C. H. (2004). Collaborative prototyping and the pricing of custom designed products. Management Science, 50(2).

University of St. Gallen (2005). Design Thinking Method Cards. https://www.slideshare.net/DTHSG/design-thinking-methodcards. Accessed 10 Mar 2017

Witt, U. (2016). What kind of innovations do we need to secure our future? Journal of Open Innovation: Technology, Market, and Complexity, 2, 17

Yun, J. J., Won, D. K., \& Park, K. B. (2016). Dynamics from open innovation to evolutionary change. Journal of Open Innovation: Technology, Market, and Complexity, 2, 7. 